\title{
Transformed Root Cultures of Solanum dulcamara L.: A Model for Studying Production of Secondary Metabolites
}

\author{
Amani M. Marzouk ${ }^{1}$,Stanley G. Deans ${ }^{2}$, \\ Robert J. Nash ${ }^{3}$ and Alexander I. Gray ${ }^{2}$ \\ ${ }^{1}$ Department of Pharmacognosy, Faculty of Pharmacy, University of Mansoura \\ 2 Phytochemistry Research Laboratories, Strathclyde Institute for Biomedical Sciences, \\ University of Strathclyde, Scotland \\ ${ }^{3}$ Institute of Grassland and Environmental Research, \\ Plas Gogerddan, Aberystwyth, Ceredigion \\ ${ }^{1}$ Egypt \\ 2,3UK
}

\section{Introduction}

Solanum dulcamara L. (dogwood or bitter sweet), Solanaceae, is one of the recommended species for growing in the temperate regions as a source of steroidal alkaloids. These alkaloids are suggested to be alternatives for diosgenin in the commercial production of steroidal pharmaceuticals (Mathé et al., 1986). Steroidal alkaloids like solasodine and its C25 epimer tomatidenol can be easily converted to pregdienolone which is an important intermediate in the synthesis of steroids (Sato et al., 1951). Solanum dulcamara L. exists in three chemovarieties that contain either solasodine, soladulcidine or tomatidenol glycosides (Willuhn, 1966). These Solanum alkaloids are always accompanied by varying quantities of their corresponding oxygen analogues, i.e. the neutral saponins. So, these chemovarities can be relisted as tomatidenol/yamogenin, solasodine/diosgenin and soladulcidine/tigogenin types (Hegnauer, 1989). The tomatidenol-producing taxa are found in the humid Atlantic climate of Western Europe, the soladulcidine type occurs in the drier continental climates while the solasodine variety is comparatively rare (J.R Mathé \& I. Mathé, 1979). Only the solasodine and tomatidenol-producing varieties are of interest, but their productivity would not be comparable to that of other tropical or subtropical species as S. laciniatum. So, if this steroidal alkaloids content could be boosted by manipulation, $S$. dulcamara could be of interest for commercial growing due to its other qualities like fair cold hardiness, good growth on poor soils and perennial life cycle. An alternative approach was to produce these alkaloids intensively in vitro. Several Solanum species including S. dulcamara were the subject of many in vitro manipulations, but attempts, which involved techniques like cell suspension and callus cultures failed to achieve the target. Secondary metabolites production, in general, needs a certain degree of tissue differentiation, something that is obviously lacking in those in vitro systems (Ehmke \& Eilert, 1993; Rhodes et al., 1987). A more promising technique has been introduced as an alternative to the classical cell 
suspension and callus cultures, the transformed or hairy roots cultures. These roots are obtained by a natural genetic transformation mechanism via the soil pathogen Agrobacterium rhizogenes (Chilton et al., 1982). A. rhizogenes is the genetic engineer which inserts a part of its root-inducing plasmid (transfer or T-DNA) into the plant genome, inducing the proliferation of the amazing hairy roots. Among the many advantages of hairy roots are rapid biomass accumulation, typically accompanied with a high production of secondary metabolites, high stability in growth characteristics and metabolic profile and the possibility for upscaling in specialized bioreactors (Georgiev et al., 2007; Hamill \& Lidgett, 1997). Few hairy root cultures which, deal with production of steroidal alkaloids are reported for Solanum species. Only those of S. elaeagnifolium, S. muritianum and S. aviculare could be traced (Alvarez et al., 1994; Argolo et al., 2000; Drewes \& Van Staden, 1995; Kittipongapatana et al., 1998; Subroto \& Doran, 1994; Yu et al., 1996). Others have also investigated the production of neutral steroidal saponins from hairy roots of S. aculeatissimum (Ikenga et al., 1995).

Another group of alkaloids has been detected in Solanum dulcamara L., fairly recently, by Asano et al., 2001. These are the calystegines. Calystegines are a class of polyhydroxy nortropane alkaloids, which are characterized by a bicyclic nortropane ring structure and unique aminoketal functionality at the bridgehead. Tepfer et al. (1988) reported, for the first time, the presence of this group of alkaloids in the underground organs and the root exudates of Calystegia sepium, Convolvulus arvensis (Convolvulaceae) and Atropa belladonna (Solanaceae). Since then, several compounds belonging to this class have been identified in plants of the families Solanaceae, Convolvulaceae and Moraceae (Asano et al., 1994, 2001; Nash et al., 1993; Schimming et al., 1998). Interest rose in studying the potential biological activities and therapeutic uses of calystegines due to their structural similarities to another class of polyhydroxylated alkaloids, which are collectively known as the sugar mimic glycosidase inhibitors. This class comprises four structural types, piperidine, pyrrolidine, pyrrolizidine and indolizidine derivatives, which are involved in a wide range of biological activities such as intestinal digestion, post-translational processing of glycoproteins, the lysosomal catabolism of glycoconjugates and have enormous therapeutic potential in many diseases such as viral infection including HIV, cancer and diabetes (Asano et al., 2000). Several calystegines were proved to have potent glycosidase inhibitory activity (Asano, et al., 1997, Watson et al., 2001). In this work we describe, for the first time, the production of steroidal and the polyhydroxy-alkaloids, calystegines, from hairy root cultures of $S$. dulcamara L. The growth characteristics of cultures and their morphology by scanning electron microscopy were also investigated.

\section{Materials and methods}

\subsection{General experimental procedures}

Plant materials were purchased from local nurseries (UK); salts for media preparation were obtained from Sigma (UK); PCR reagents were obtained from Perkin Elmer (UK); primers from VH Bio Ltd (UK); Perkin Elmer GeneAmp 480 thermal cycler (UK) was used for DNA amplification; Column chromatography was performed on silica gel (Merck, 70-230 mesh) and Sephadex LH-20 (Sigma, UK); TLC was performed on precoated TLC plates with silica gel $60 \mathrm{~F}_{254}$ (Merck, $0.25 \mathrm{~mm}$, USA); solvents for chromatography were reagent grade; ${ }^{1} \mathrm{H}$ and ${ }^{13} \mathrm{C}-\mathrm{NMR}$ spectra (400 and $100 \mathrm{MHz}$, respectively) were acquired on Bruker dpx 400 spectrometer using pyridine- $\mathrm{d}_{5}$ or $\mathrm{D}_{2} \mathrm{O}$ as solvents; samples for SEM were gold coated in Polaron E5350; SE micrographs were taken using a Joel JSM T220 scanning electron microscope; standard solasodine (Koch-Light laboratories, UK) and diosgenin (Sigma, UK). 


\subsection{Establishment of transformed root cultures}

Transformed roots were obtained by infecting surface sterilised leaf and stem segments with Agrobacterium rhizogenes strain A4 (a kind gift from Dr A. Petit, Laboratoire De Biologie De La rhizosphere, Versailles Cedex, France in 1998). Strain A4 harbours the root inducing plasmid pRiA4 and was engineered to contain in addition plasmid Bin 19, which harbours a kanamycin-resistant gene as a selectable marker. An overnight bacterial suspension in yeast mannitol broth (YMB) (Hooykaas et al., 1977) supplemented with $50 \mu \mathrm{M}$ acetosyringone (as virulence inducer) was used for inoculation into freshly wounded explants. Infected samples were transferred to one tenth Murashige and Skoog (MS) agar solidified media (Murashige \& Skoog, 1962), kept in the dark for $48 \mathrm{~h}$ then incubated under $16 \mathrm{~h}$ photoperiod at light intensity of approximately $1.8 \mathrm{wm}^{-2}$ at $20 \pm 2{ }^{\circ} \mathrm{C}$. The putative hairy roots, were transferred to hormone-free MS liquid media supplemented with $30 \mathrm{~g} \mathrm{l}^{-1}$ sucrose. Ampicillin sodium salt $500 \mathrm{mg} \mathrm{l}^{-1}$ was added until cultures were free from the residual bacteria. The putative transgenic roots were maintained on the same liquid media (50 ml in $250 \mathrm{ml}$ flasks) on gyratory shakers (90 $\mathrm{rpm}$ ), at $20 \pm 2{ }^{\circ} \mathrm{C}$ in the dark or under illumination for $16 \mathrm{~h}$ day ${ }^{-1}$ or under continuous light. The roots were sub-cultured every two weeks. For isolation of compounds, roots were inoculated into 51 flasks containing 21 of Gamborg's B5 liquid media, aerated with a bubble-type sparger and incubated for a period of four weeks in the dark. Some root samples were subcultured and maintained in other liquid media, viz. B5 and SH (Gamborg's B5 and Schenk and Hildebrandt) (Gamborg, et al. 1968; Schenk \& Hildebrandt, 1972) for purpose of comparison.

\subsection{Confirmation of transformation by Polymerase Chain Reaction (PCR)}

Genomic DNA was extracted from $100 \mathrm{mg}$ (fresh wt.) of putative hairy roots and normal non-transformed roots (as controls) using commercially available plant DNA extraction kit (Nucleon-Phytopure, UK). These DNAs were used as templates for the reaction. PCR was performed with rol B gene specific primers: 5-ATG GAT CCC AAA TTG CTA TTC CTT CAA CGA-3`and 5-TAA GGC TTC TTT CTT CAG GTT TAC TGC AGC-3` (VH bio Ltd, UK). Amplification was carried out according to Hamill et al. (1990). Products of the reaction were run on $1.5 \%$ agarose electrophoretic gel stained with ethidium bromide, along with a standard DNA marker.

\subsection{Growth rate analysis}

Growth rate analysis, for some root lines which showed good growth characteristics in liquid media, was determined by both dry weight and the dissimilation methods according to Schripsema et al., 1990.

\subsection{Scanning electron microscopy}

Fresh hairy root material was fixed with $1.5 \%$ glutaraldehyde (GA) in $0.05 \mathrm{M}$ sodium cacodylate buffer, $\mathrm{pH} 7.0$, for $45 \mathrm{~min}$. After 1 - $2 \mathrm{~min}$ in vacuum $(26 \mathrm{~mm} \mathrm{Hg}, 3.46 \mathrm{kPa})$ the fixative was substituted by $3 \%$ GA in $0.1 \mathrm{M}$ cacodylate buffer, $\mathrm{pH} 7.0$ for $2 \mathrm{~h}$. The material was then post-fixed in $1 \%$ aqueous solution of osmium tetroxide for $2 \mathrm{~h}$. All treatments were carried out at room temperature. The fixed material was dehydrated in graded ethanol series, dried by the critical point drying method and sputter coated with gold before observation in the electron microscope (Ascenão et al., 1998). 


\subsection{Extraction and isolation of steroidal compounds}

Fresh root material (400 g), grown in B5 liquid media and incubated in dark, was extracted with cold methanol $(\mathrm{MeOH})$ overnight $(11 \times 3)$. The combined methanolic extracts were concentrated under vacuum at $40{ }^{\circ} \mathrm{C}$, partitioned between distilled water and petroleum ether, $\mathrm{CHCl}_{3}$ and finally with $n$-butanol. The $n$-butanol fraction (3.1 g) was column chromatographed on silica gel using vacuum liquid chromatography. Fractions eluted with $15 \% \mathrm{MeOH}$ in $\mathrm{CHCl}_{3}(220 \mathrm{mg})$ were further chromatographed on Sephadex LH-20 using mixtures of $\mathrm{CHCl}_{3} / \mathrm{MeOH}$ of increasing polarity. Fractions eluted with $8 \% \mathrm{MeOH}(54 \mathrm{mg})$ were further purified on preparative TLC plates using $\mathrm{CHCl}_{3}-\mathrm{MeOH}-\mathrm{H}_{2} \mathrm{O}$ (70:30:0.5) for development to yield compound 1 (22 mg, $\mathrm{R}_{f}$ 0.46, $\left.\mathrm{CHCl}_{3}-\mathrm{MeOH}-\mathrm{H}_{2} \mathrm{O}, 70: 30: 3\right)$ and compound 2 (6 mg in a mixture, $\left.\mathrm{R}_{f} 0.43, \mathrm{CHCl}_{3}-\mathrm{MeOH}-\mathrm{H}_{2} \mathrm{O}, 70: 30: 3\right)$.

\subsection{Determination of total steroids}

\subsubsection{Determination of steroidal bases}

A spectrophotometric assay adopted from a method described by Briner, 1969 and modified by Crabbe \& Fryer, 1982, was followed. The method depends on formation of a coloured complex of the steroidal bases with methyl orange, after acid hydrolysis of the glycosides in the extract and its spectrophotometric measurement at $425 \mathrm{~nm}$. Determination of the concentration of test samples was achieved by constructing a calibration curve using standard solasodine base.

\subsubsection{Determination of neutral sapogenins}

A specific spectrophotometric analysis method for the determination of the total steroidal sapogenins, after acid hydrolysis, was followed. This method is based on chromophore formation with a reagent composed of anisaldehyde and sulphuric acid. The produced colour has one absorbance peak at $430 \mathrm{~nm}$. The method is capable of determining different sapogenin types of different structures, irrespective of differences in stereochemistry at rings $\mathrm{E}$ and $\mathrm{F}$, rings $\mathrm{A} / \mathrm{B}$ conformation, presence or absence of unsaturation at C5-C6 or presence of keto or hydroxyl groups at C-3. Other compounds like sterols, triterpenoid sapogenins and/or sugars from glycosides, do not interfere with the determination. The reaction with the chromogen is believed to be restricted to rings $E$ and F (Baccou et al., 1977). Determination of the concentration of test samples was achieved by constructing a calibration curve using standard diosgenin.

\subsection{Investigation of calystegines content}

\subsubsection{Sample preparation}

Oven dried samples $\left(70{ }^{\circ} \mathrm{C}\right), 10 \mathrm{~g}$ each, of roots grown under light and in dark were extracted with $50 \%$ aqueous methanol $(100 \mathrm{ml} \times 3)$ for $12 \mathrm{hr}$. The hydro-methanolic extract in each case was filtered and concentrated to a syrupy consistency under vacuum at $40^{\circ} \mathrm{C}$. The extracts were partially purified by ion exchange chromatography on a strong acidic resin, Dowex-50W in the $\mathrm{H}^{+}$form. Each extract was loaded onto glass columns packed with the resin and unbound material (sugars and phenolic compounds) was washed through with distilled water. The bound fraction (basic compounds and calystegines) was eluted with $2 \mathrm{M}$ ammonium hydroxide solution. Ammonia was removed from the samples by evaporation under vacuum at $40^{\circ} \mathrm{C}$. Each sample was then processed for GC-MS analysis as follows. 


\subsubsection{Sample derivatisation for GC-MS}

Small aliquots of the above-purified bound fraction $(1 \mathrm{ml}$ each) were freeze-dried. The freeze-dried samples were silylated using $100 \mu \mathrm{l} \mathrm{mg}^{-1}$ of Sigma-Sil A reagent (Sigma, UK), which consisted of a mixture of trimethylchlorosilane $\left[\left(\mathrm{CH}_{3}\right)_{3} \mathrm{Si} \mathrm{Cl}\right]$, hexamethyldisilizane $\left[\left(\mathrm{CH}_{3}\right)_{3} \mathrm{Si} \mathrm{NH} \mathrm{Si}\left(\mathrm{CH}_{3}\right)_{3}\right]$ and pyridine in the ratio of 1:3:9. Samples were mixed using a vortex mixer and then heated at $55^{\circ} \mathrm{C}$ for 15 minutes. The reaction mixture was cooled down to room temperature for at least one hour and then centrifuged at $2 \times 10^{3} \mathrm{rcf}$ for 20 minutes to remove any precipitate formed during the reaction. The supernatants were then transferred to GC vials and analysed by GC-MS as follows: a BPX5 25m capillary column, $0.22 \mathrm{~mm}$ ID, film thickness $0.25 \mu \mathrm{m}$ (SGE Ltd., UK) was used, helium at a pressure of $10 \mathrm{psi}$. Temperature programme started with an isothermal hold at $180{ }^{\circ} \mathrm{C}$ for 5 minutes, followed by a linear temperature rise to $300{ }^{\circ} \mathrm{C}$ at $10{ }^{\circ} \mathrm{C} / \mathrm{min}$. The final temperature was held for 10 minutes and the total length of the program was 27 minutes. Samples were introduced at 1.0 $\mu \mathrm{l}$ per injection. EI-MS of the column effluent was carried out on Perkin-Elmer Q-Mass 910 Benchtop Mass Spectrometer with quadruple mass filter system. The system was set to a constant temperature of $280^{\circ} \mathrm{C}$. The effluent from the gas chromatograph was transferred to the mass spectrometer via a temperature controlled line set at $250{ }^{\circ} \mathrm{C}$.

\subsubsection{Large scale fractionation}

The calystegine-containing fraction from $500 \mathrm{~g}$ fresh hairy roots of $S$. dulcamara was prepared as above. The bound material eluted from Dowex-50W was fractionated on weakly acidic cation exchanger (Amberlite CG-50, $\mathrm{H}^{+}$) using water as an eluant. The column was finally washed with dilute ammonium hydroxide solution to elute the strongly bound bases. Fractions collected from the CG-50 column were further purified by extensive ion exchange chromatography on either weakly acidic $\left(\mathrm{CG}-50, \mathrm{H}^{+}\right.$) or weakly basic (Dowex-2x8, Cl-) resins using water for elution and a final rinsing with dilute ammonium hydroxide solution. Small aliquots of each fraction were freeze-dried and derivatized for GC-MS analysis as described above.

\subsubsection{GC-MS data for calystegines}

Calystegine $\mathbf{A}_{3}: \mathrm{R}_{\mathrm{t}}$ (4.95 minutes), EI/MS (positive mode) at m/z (rel. intensity) 286 (8), 244 (20), 170 (12), 156 (100), 147 (9).

Calystegine $A_{5}: R_{t}$ (4.54 minutes), EI/MS (positive mode) at m/z (rel. intensity) 286 (15.4), 244 (17), 169 (15), 156 (100), 147 (17).

Calystegine $\mathbf{B}_{1}: \mathrm{R}_{\mathrm{t}}(7.28$ minutes), EI/MS (positive mode) at $\mathrm{m} / \mathrm{z}$ (rel. intensity) 373 (19.5), 332 (29), 285 (6), 258 (23), 244 (100), 168 (17), 147 (26), 129 (63).

Calystegine $\mathbf{B}_{2}: \mathrm{R}_{\mathrm{t}}(8.70$ minutes), EI/MS (positive mode) at $\mathrm{m} / \mathrm{z}$ (rel. intensity) 284 (11), 259 (14), 229 (8), 217 (100), 204 (8), 156 (20), 147 (21).

Calystegine $\mathbf{B}_{1}$ glucoside: $\mathrm{R}_{\mathrm{t}}(14.65$ minutes), EI/MS (positive mode) at $\mathrm{m} / \mathrm{z}$ (rel. intensity) 430 (38), 316 (100), 287 (38), 217 (76), 205 (38), 156 (25), 147 (79).

Calystegine $\mathbf{A}_{3}\left(\mathbf{A}_{5}\right)$ glycoside: $\mathrm{R}_{\mathrm{t}}(14.74$ minutes), EI/MS (positive mode) at $\mathrm{m} / \mathrm{z}$ (rel. intensity) 286 (100), 244 (6), 217 (12), 204 (12), 169 (8), 156 (65), 147 (19), 129 (8).

\subsection{5 ${ }^{13} \mathrm{C}$ data for Calystegine $\mathrm{B}_{2}$}

(100 MHz, $\mathrm{D}_{2} \mathrm{O}$ and drops of acetone- $\mathrm{D}_{6}$ for signal calibration, $\delta$ values in ppm): $\delta 90.0(\mathrm{C} 1)$, 74.5 (C2), 74.6 (C3), 77.3 (4), 55.5 (C5), 21.3 (C6), 28.4 (C7). 


\section{Results and discussion}

\subsection{Transformation}

Secondary metabolites production, in general, needs a certain degree of tissue differentiation, something that is obviously lacking in dedifferentiated in vitro systems, like callus and cell suspension cultures. For example, Ehmke and Eilert (1993) did not detect any alkaloids in cell suspension cultures of $S$. dulcamara L. grown in dark. These alkaloids started to be synthesized when the cultures were grown in light and began to show some differentiation and rooting, but their level was not comparable to the original intact plant. A more promising technique has been introduced as an alternative to the classical cell suspension culture that is transformed or hairy root cultures. These roots are obtained by a natural genetic engineering mechanism via the soil pathogen Agrobacterium rhizogenes. The produced hairy roots are genetically and chemically stable and are characterized by high productivity of secondary metabolites, which in most cases mirrors that of the original nontransformed plant (Hu \& Du, 2006). Hence, a transformed root culture was established for $S$. dulcamara. The putative hairy roots appeared on the infected stem segments as early as one week after infection, in some of the samples, and were complete within two weeks in the rest of them. Some roots appeared directly from or near the wounding sites and some differentiated from small calli, which formed at the wounding sites (Fig. 1, A). No hairy roots appeared on the infected leaf segments; instead, green normal roots were developed from the cut ends of the midribs and from the basal parts of the infected as well as the control samples of the leaves and the stems. These normal roots failed to grow when transferred to liquid media lacking growth hormones, which confirmed their untransformed nature. Although solanaceous plants are reported to be highly susceptible to infection with A. rhizogenes (Porter, 1991), the transformation frequency obtained by us with $S$. dulcamara $(>93 \%)$ far exceeds transformation rates reported for other Solanum species. For example, Drewes \& Van Staden (1995) obtained only one transformation event out of 80 infected samples of $S$. mauritianum Scop., whether acetosyringone was used or not, while Argolo et al. (2000) managed to obtain 20-90 \% transformation frequency for S. aviculare Forst. depending on the bacterial strain used for infection.

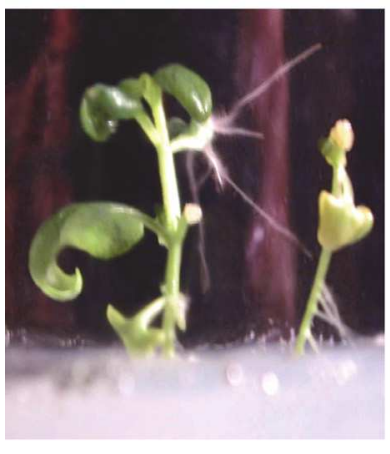

A.

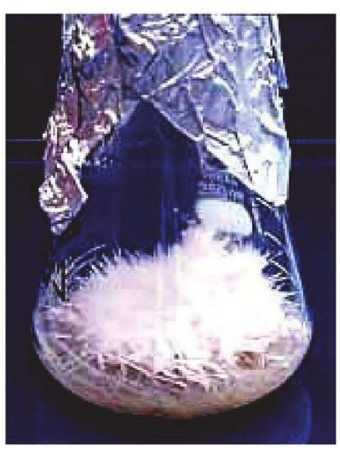

B.

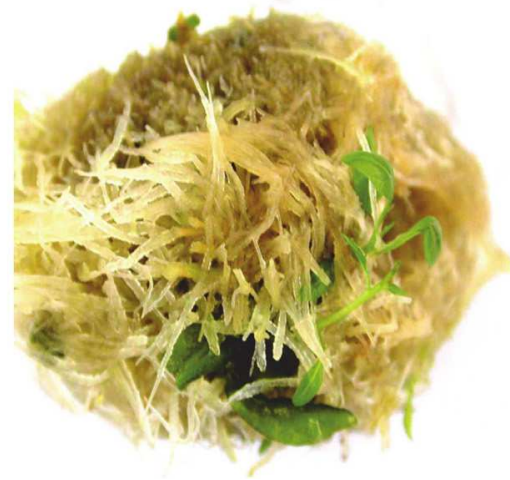

C.

Fig. 1 A. Initiation of hairy roots on infected stem segments with A. rhizogenes; B. Hairy roots in liquid culture; C. Regenerated shoots from roots grown in continuous light 
Roots incubated under photoperiod showed greening and those incubated under continuous light regenerated small shoots within four weeks (Fig. 1, C). Roots grown in different liquid media, MS, B5 and SH (Fig.1, B) displayed typical properties of transformed roots, i.e. fast growth, high degree of branching, abundant root hairs and lack of positive geotropism. Insertion of the root inducing plasmid was confirmed by PCR using primers specific to rol B gene (root-inducing locus). Results showed amplification band expected for that gene $(0.78 \mathrm{~kb})$, while normal non-transformed roots used as controls did not show any amplification bands (Fig. 2).

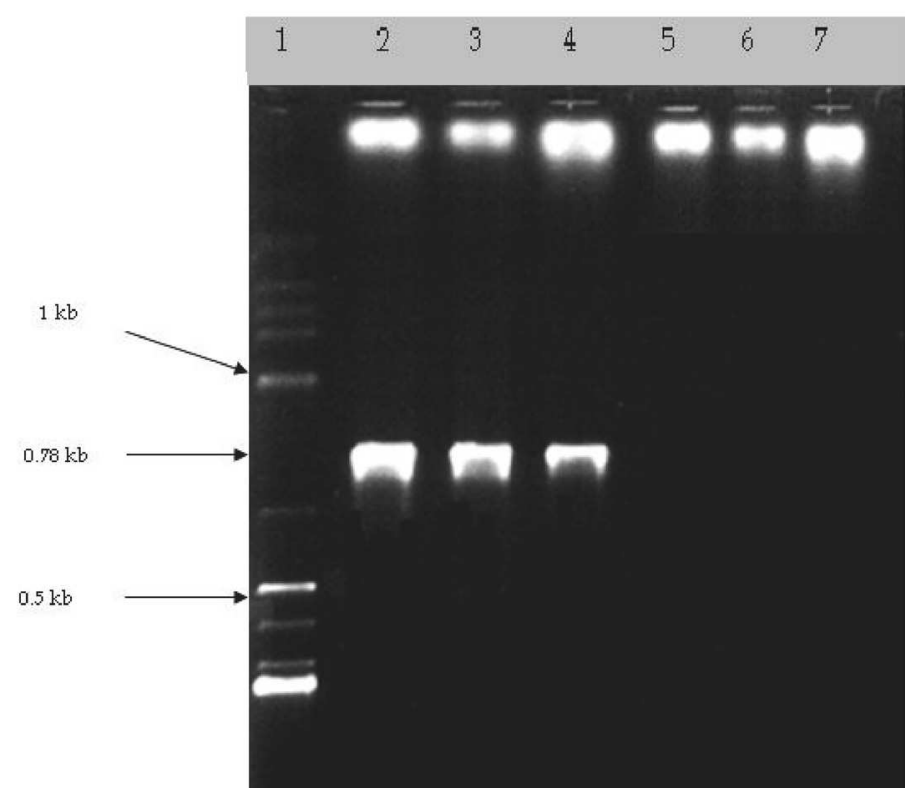

Fig. 2. PCR products of $S$. dulcamara. Lane1, DNA marker; lanes 2-4, DNA from hairy roots (1-3 $\mu \mathrm{L})$; lanes, 5- 7, DNA from normal roots (1-3 $\mu \mathrm{L})$.

\subsection{Growth characteristics of the cultures}

Growth rate analysis of the transformed root cultures was performed using two methods. The first, depended on determination of the dry mass accumulation over a period of four weeks and the second, involved determination of the growth characteristics by the dissimilation method i.e. determination of the loss of carbon dioxide due to carbohydrate consumption. Growth rate determination by the dissimilation method was carried out in three different liquid media (MS, B5 and SH) either under dark or light conditions. None of the cultivation media was inhibitory to the growth of the transformed roots, but differences were observed in the growth rate among these media. Roots showed best growth characteristics in MS media incubated under light conditions and in Gamborg's B5 media under dark conditions (Fig. 3, A \& B). The cultures showed a very short lag phase of less than two days and continued an active exponential phase for 17 days before entering a stationary phase. Generally, roots grown under dark conditions grew more actively, except for roots grown in $\mathrm{SH}$ media (Fig. 3, A \& B). Growth rate determination by dry mass 
accumulation method (Fig.4) showed a similar pattern of growth with a 45-fold increase in root mass per flask, with an inoculum size of $200 \mathrm{mg}$ fresh roots. The results demonstrate the importance of selection of the hairy root clones and also the possibility to manipulate the cultures through media selection and incubation conditions. The different clones are derived from different transformation events as a result of the insertion of the T-region of the root inducing plasmid, which is known to be a random process. This variability makes the hairy root system as amenable and flexible to manipulation as the dedifferentiated cell cultures, but having the advantage of still being an organised system with certain degree of maturation that allows expression of the enzymatic systems leading to the different secondary metabolic pathways.

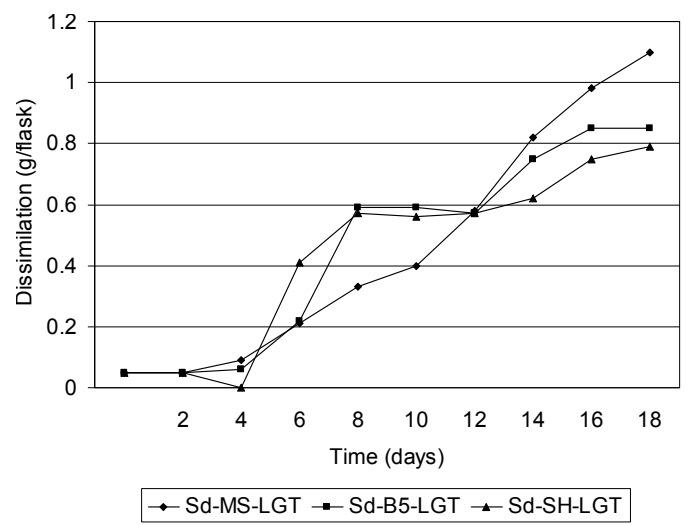

A

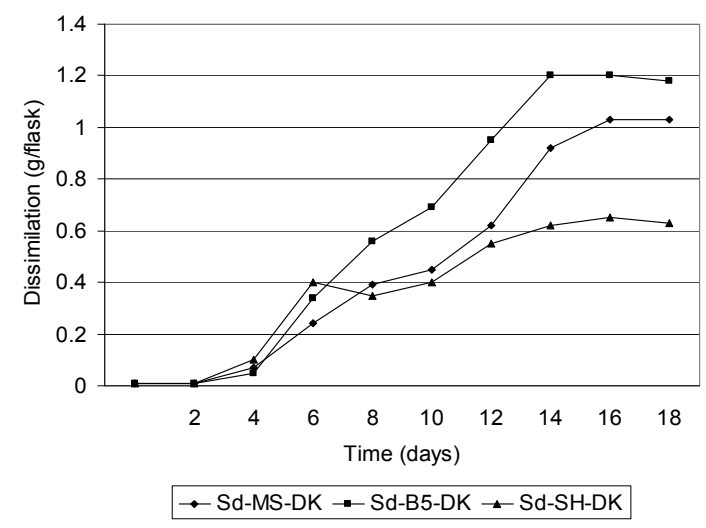

B

Fig. 3. Growth rate analysis of hairy roots in different media; A, under light; B in dark (dissimilation method). 
Transformed Root Cultures of Solanum dulcamara L.:

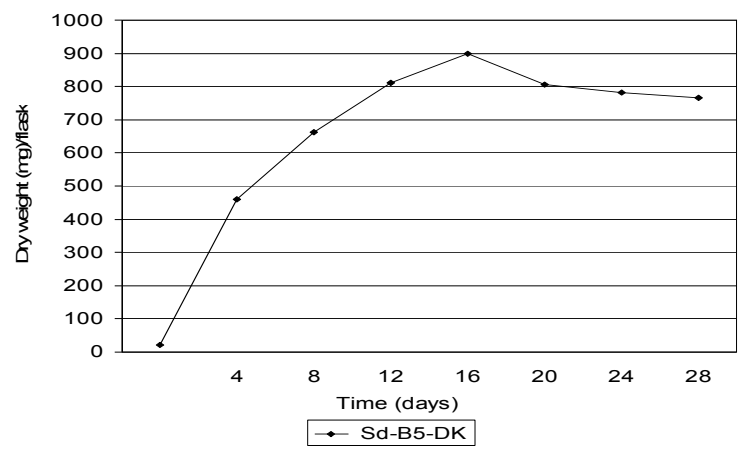

Fig. 4. Growth rate analysis of hairy roots in B5 media in dark (Dry weight method).

\subsection{Scanning Electron Microscopy (SEM)}

SEM of the transformed roots (Fig. 5) showed high degree of branching and large number of root hairs. Some of the hairs appeared as long unicellular tubes, while others like short papillae covering the majority of the roots surfaces, especially those growing near and out of the surface of the media. Cut surfaces of the roots, revealed the structure of young dicot root with abundant starch granules and microcrystals of calcium oxalates in the cortical parenchyma (not shown). These cell inclusions which are characteristic features of plants belonging to the family Solanaceae (Metcalf \& Chalk, 1957) reflect genetic stability of the transformed cultures as they retain the histological fingerprints of the mother plant. The high degree of branching and the abundant root hairs are typical characteristics of transformed roots.

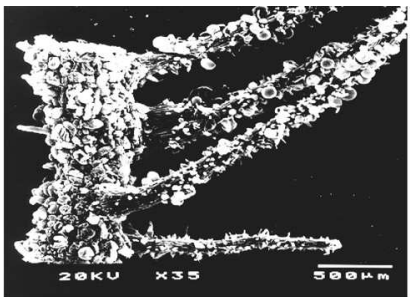

Branched root segment

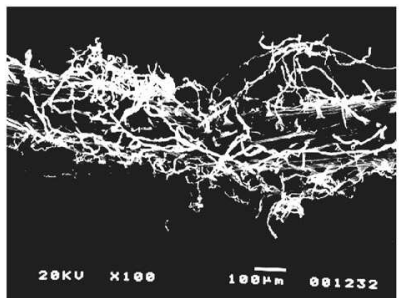

Long root hairs

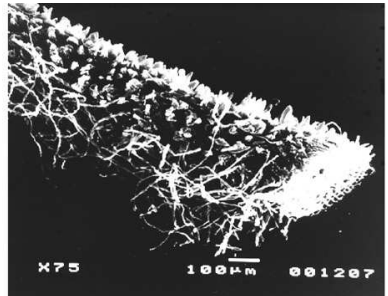

Short root hairs
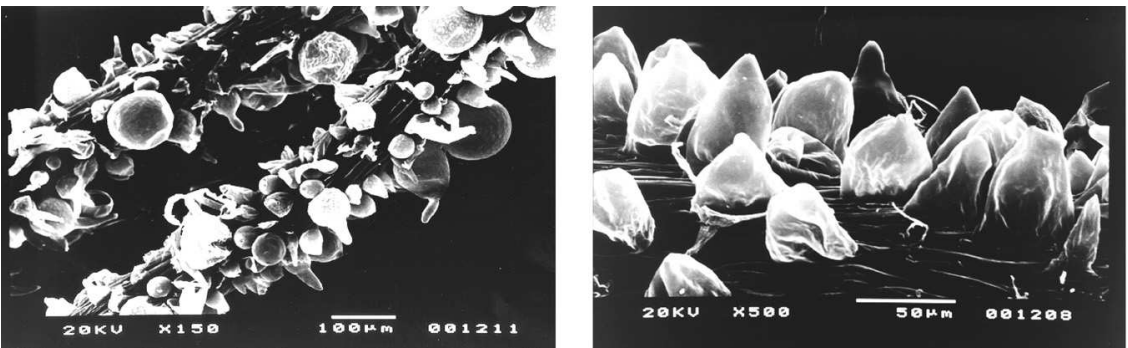

Magnification of short root hairs

Fig. 5. Scanning electron micrographs of different root hairs. 


\subsection{Investigation of the produced secondary metabolites 3.4.1 Steroidal compounds}

Chromatographic investigation (TLC) of the methanolic extracts of the transformed roots and different parts of the non-transformed plant (roots, aerial parts and fruits) showed almost similar pattern of secondary metabolites with one major alkaloidal spot and several minor ones. Analytical HPLC (data not shown) revealed much more complex profile of the hairy root extracts. No qualitative differences were observed for transformed roots grown in different liquid media or for roots grown in the dark and those grown in light, except for the formation of higher amounts of less polar compounds in the roots grown in dark (higher percentage of chloroform extractives, data not shown). Chromatographic separation of the $n$-butanol extract of roots grown in dark in B5 liquid media lead to the isolation of two compounds, 1 and 2. Compound 1 was obtained as amorphous solid, yield $0.0055 \%,(\mathrm{w} / \mathrm{w}$, on fresh wt. basis), positive Dragendorff's and was identified as (25S)-3- $\beta-\{[O-\alpha-\mathrm{L}-$ rhamnopyranosyl-(1“ $\rightarrow 2$ ')-O- $\alpha$-L-rhamnopyranosyl-( $\left.1^{\cdots} \rightarrow 4\right)$ ]- $\beta$-D-glucopyranosyloxy $\}$ $22-\beta-\mathrm{N}$-spirosol-5-ene, ( $\beta$-solamarine or tomatidenol-3-O- $\beta$-chacotrioside), based on spectroscopic data. Positive FAB MS exhibited a base peak at $\mathrm{m} / \mathrm{z} 868[\mathrm{M}+1]^{+}$, corresponding to the molecular formula $\mathrm{C}_{45} \mathrm{H}_{73} \mathrm{O}_{15} \mathrm{~N}$. EI mass spectrum displayed fragment ions at $\mathrm{m} / \mathrm{z} 114(90 \%)$ and $\mathrm{m} / \mathrm{z} 138$ (65\%) characteristic of spirosolane-type alkaloids. The first fragment arises from the cleavage of the cyclic ether ring (ring E) at C20, C22 and C22-O sites. The latter results from cleavage of ring D (Atta-ur-rahman \& Choudhary, 1993).Thus the mass spectral data suggested $\mathbf{1}$ to be a glycoalkaloid of the spirosolane-type. ${ }^{1} \mathrm{H}-\mathrm{NMR}$ spectrum (Table 2) displayed proton resonances characteristic of a steroid aglycone of the spirosolenol type, in addition to sugar protons. Some of the diagnostic proton resonances associated with the aglycone was observed as two tertiary methyl singlets at $\delta 0.80$ and $\delta 1.06$ attributable to the methyl groups at positions C18 and C19 of the steroid nucleus, respectively. Two secondary methyl signals at $\delta 1.10(\mathrm{~d}, J=8.2 \mathrm{~Hz})$ and $\delta 0.81(\mathrm{~d}, J=7.2 \mathrm{~Hz})$ were assigned to methyls at C21 and C27, respectively. A broad singlet at $\delta 5.34$ was assigned to the olefinic proton at $\mathrm{C} 6$ and a multiplet at $\delta 3.90$ to proton at $\mathrm{C} 3$. The ${ }^{1} \mathrm{H}-\mathrm{NMR}$ spectrum showed further resonances associated with sugar protons. Two broad singlets at $\delta$ 5.86 and $\delta 6.40$ are characteristic of the anomeric protons of $\alpha$-linked sugars. The observation of another two upfield secondary methyl signals at $\delta 1.64(\mathrm{~d}, J=6.1 \mathrm{~Hz})$ and $\delta 1.78(\mathrm{~d}, J=6.1$ $\mathrm{Hz}$ ) suggested two molecules of 6-deoxy sugars. A third anomeric proton observed at $\delta 4.94$ $(\mathrm{d}, J=8.0 \mathrm{~Hz}$ ), typical of $\beta$-linked glucose, and showed a direct correlation to an anomeric sugar carbon at $\delta 100.8$ in HMQC experiment. This indicated a glycoalkaloid with a trisaccharide moiety. The ${ }^{13} \mathrm{C}$ spectrum supported by APT measurements (Table 3) showed 45 carbon resonances, among them 27 carbons were assigned to the aglycone part. Those included signals due to a spiro carbon at $\delta 98.9$, assigned to $\mathrm{C} 22$ and olefinic carbons at $\delta$ 122.3 and 141.3, assigned to C6 and C5, respectively. The remaining carbon signals in the spectrum could be assigned to three sugar moieties, a hexose and two 6-deoxy sugars. The direct connectivity of the protons and the carbon atoms were revealed through HMQC experiment. The identity of the aglycone part as well as the that of the building blocks of the glycosidic moiety and the interglycosidic linkages were confirmed through HMBC experiment (Fig. 6) as follows: many parts of ring A were defined by observation of cross peaks between a complex signal centred at $\delta 2.75$ assigned to the two protons at $\mathrm{C} 4$ and carbon signals at $\delta 38.0$ (C10), 78.6 (C3) and 122.3 (C6) and a further 2J coupling with a quaternary carbon signal at $\delta 141.3(\mathrm{C} 5)$, the latter two correlations confirmed unsaturation 
between C5 and C6 and indicated a derivative of either solasodine or its 25-epimer tomatidenol. Another cross peak between one of the methyl singlets at $\delta 1.06$ (Me-19) and a carbon resonance at $\delta 37.7$ confirmed the latter position as $\mathrm{C} 1$. The position of $\mathrm{C} 17$ was also confirmed by the observation of another 3J coupling with the methyl doublet at $\delta 1.10$ (proton at C21). This doublet showed a further 2J coupling to the Spiro carbon at $\delta 98.8$ assigned to $\mathrm{C} 22$. The positions of the carbons of ring F were assigned also through HMBC. $3 J$ cross peaks were observed between the doublet at $\delta 0.81$ (methyl at C27) and carbon signals at $\delta 29.8$ (C24) and 51.1 (C26) and another 2J coupling with C25 ( $\delta 32.1)$. Comparison of the spectral data for the aglycone part with those for standard solasodine and tomatine performed in the same solvent (pyridine- $\mathrm{d}_{5}$ ) revealed close resemblance to those of the aglycone part of tomatine except for the presence of a double bond between C5 and C6. Furthermore, the NMR spectral data for the aglycone part of $\mathbf{1}$ were found to be in good agreement with those published for tomatidenol tetraoside (Usubillaga et al., 1997). The HMBC spectrum in the sugar region (Fig. 6) showed that the anomeric proton at $\delta 4.94(\mathrm{~d}, J$ $=8.0 \mathrm{~Hz}$ ), which was showed by the HMQC experiment to be connected to a sugar anomeric

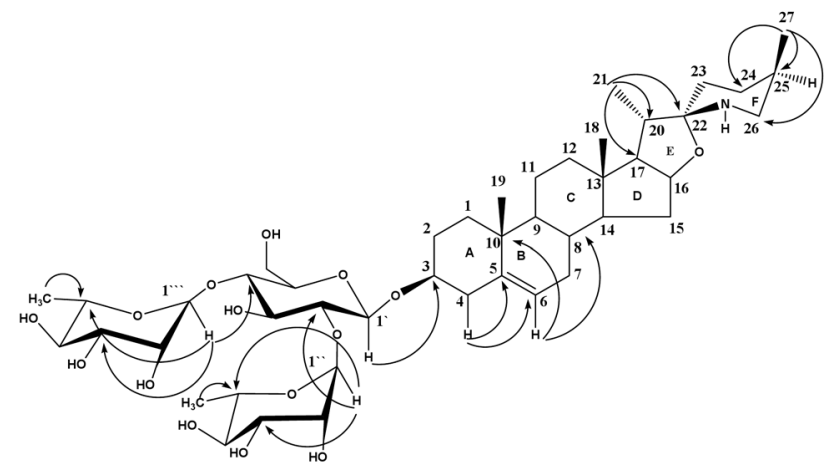

Fig. 6. HMBC correlations observed for $\beta$-solamarine, 1

carbon at $\delta 100.8$, correlated to a carbon resonance at $\delta 78.6$ (C3). The downfield shift observed for C3 (about $8.0 \mathrm{ppm}$ ) from that published for free aglycones (70.5 - $71.3 \mathrm{ppm}$ ) confirmed glycosylation at this carbon (Toshinori et al., 1993; Ripperger, 1996). Mutually the proton at $\mathrm{C} 3$ of the steroid nucleus (multiplet at $\delta 3.90$ ) correlated to the sugar anomeric carbon at $\delta$ 100.8. The proton and carbon shifts of the other two sugars (Tables 1 and 2) suggested that they are rhamnoses. Cross peaks in the HMBC spectrum between the anomeric protons of the two rhamnoses ( $\delta 6.40$ and 5.86, br s) and carbon signals at $\delta 78.4$ ppm and $\delta 79.1$ confirmed that those sugars were attached to glucose through $\left(1^{\prime \prime} \rightarrow 2^{\prime}\right)$ and $\left(1^{\prime \prime} \rightarrow 4\right)$ linkages. Other important correlations in the sugar region were observed between the anomeric protons of rhamnoses and $\mathrm{C} 5$ and $\mathrm{C} 3$ of both sugars and also between protons at $\mathrm{C} 6$ of the same sugars and the corresponding $\mathrm{C} 4$ and 2J couplings to $\mathrm{C} 5$. Protons at $\mathrm{C} 4$ of the rhamnose molecules showed similar $3 \mathrm{~J}$ couplings to the corresponding C6. Another correlation between $\mathrm{H} 4$ ' of glucose $(\delta 4.33-4.39, \mathrm{~m})$ and $\mathrm{C} 1$ of the same molecule (carbon signal at $100.8 \mathrm{ppm}$ ) was observed. The evidence derived from these spectral data led to the identification of 1 as (25 S)-3- $\beta$ - $\left\{\left[\mathrm{O}-\alpha\right.\right.$-L-rhamnopyranosyl-( $\left(1^{\prime \prime} \rightarrow 2^{\prime}\right)$-O- $\alpha$-L-rhamnopyranosyl$\left.\left(1^{\cdots} \rightarrow 4^{`}\right]-\beta-D-g l u c o p y r a n o s y l o x y\right\}-22 \beta-N-s p i r o s o l-5-e n e$ ( $\beta$-Solamarine or tomatidenol-3- $\beta$ - 
D-chacotrioside). This compound has been identified before in the tomatidenol variety by Rönsch and Schreiber (1966). Compound 2 could be the oxygen analogue of $\mathbf{1}$ based on giving negative reaction with Dragendorff's reagent and the detection of a carbon resonance at $\delta 108.0$ in its ${ }^{13} \mathrm{C}$-NMR spectrum (C22 of neutral saponins) and close NMR data to those of $\mathbf{1}$, but it needs further purification.

These results demonstrate the metabolic stability of the cultures, where preliminary investigations showed no major differences between hairy roots and the original plant. Other work on S. dulcamara shooty teratoma cultures obtained by transformation via A. tumefaciens revealed alteration of soladulcidine to solasodine-type glycosides (Atta-urrahman \& Choudhary, 1993). The total yield of steroids in our cultures, which ranged from approximately 2 to $7 \mathrm{mg}$ g- 1 (Table 1), is still below the requirement for commercial exploitation, so other methods of manipulating the cultures should be tried out.

\begin{tabular}{lcc}
\hline \multicolumn{1}{c}{ Sample } & Alkaloids & Sapogenins \\
\hline B5 media in dark & $4.29 \mathrm{a}$ & $2.52^{\mathrm{a}}$ \\
B5 media under light & 0.60 & 1.24 \\
SH media in dark & 2.90 & 1.19 \\
SH media under light & 0.96 & 0.59 \\
MS media in dark & 0.57 & 1.89 \\
MS media under light & 0.52 & 1.50 \\
Normal roots & 4.14 & 1.37 \\
Aerial parts & 3.28 & 2.11 \\
\hline
\end{tabular}

Table 1. Alkaloids and neutral sapogenins in hairy roots and normal plant organs. a $\mathrm{mg}$ g-1 (Dry wt.).

\begin{tabular}{cccc}
\hline $\mathrm{H}$ & $\delta \mathrm{ppm}$ & $\mathrm{H}$ & $\delta \mathrm{ppm}$ \\
\hline 1 & $1.01, d d(14.3,3.4), 1.77 \mathrm{a}$ & 24 & $1.57-1.59 \mathrm{a}, m$ \\
2 & $1.86 \mathrm{a}, 2.11^{\mathrm{a}}$ & 25 & $1.89, m$ \\
3 & $3.90, m$ & 26 & $2.83 \mathrm{a}, m, 2.95 \mathrm{a}, m$ \\
4 & $2.71, m, 2.80^{\mathrm{a}}, m$ & 27 & $0.81, d(8.2)$ \\
5 & - & 1 & $4.94, d,(8.0)$ \\
6 & $5.34 \mathrm{br} \mathrm{s}$ & 2 & $4.37 \mathrm{a}, m$ \\
7 & $1.46 \mathrm{a}, m, 1.89 \mathrm{a}, m$ & 3 & $4.33-4.39 \mathrm{a}, m$ \\
8 & $1.52-1.54 \mathrm{a}, m$ & 4 & $4.33-4.39 \mathrm{a}, m$ \\
9 & $0.92, m$ & 5 & $3.66 \mathrm{a}$ \\
10 & - & 6 & $4.10,4.23, d d(3.6,13.2)$ \\
11 & $1.46-1.47 \mathrm{a}, m$ & 1 & $6.40 \mathrm{~s}$ \\
12 & $1.12, m, 1.68-1.76 \mathrm{a}, m$ & $2 \cdots$ & $4.69, b r \mathrm{~s}$ \\
13 & - & $3 \cdots$ & $4.55, d d(3.2,13.4)$ \\
\hline
\end{tabular}


Transformed Root Cultures of Solanum dulcamara L.:

\begin{tabular}{cccc}
\hline 14 & $1.10 \mathrm{a}, m$ & $4{ }^{\prime}$ & $4.33, d d(9.4,9.4)$ \\
15 & $1.56 \mathrm{a}, m, 1.94 \mathrm{a}, m$ & $5{ }^{\prime \prime}$ & $4.93-4.99 \mathrm{a}, m$ \\
16 & $4.18 \mathrm{a}, m, 4.23 \mathrm{a}, m$ & $6^{\prime \prime}$ & $1.78 d(6.1)$ \\
17 & $1.82-1.84 \mathrm{a}, m$ & $1 \cdots$ & $5.86 \mathrm{brs}$ \\
18 & $0.83 s$ & $2 \cdots$ & $4.84, d d(1.5,4.0)$ \\
19 & $1.06 s$ & $3^{\cdots}$ & $4.64, d d(3.2,13.2)$ \\
20 & $1.96-2.02 d q(8.6,7.4)$ & $4 \cdots$ & $4.39, d d(9.4,9.4)$ \\
21 & $1.10, d(7.24)$ & $5^{\cdots}$ & $4.93-4.99 \mathrm{a}, m$ \\
22 & - & $6^{\cdots}$ & $1.64, d(6.1)$ \\
23 & $1.75 \mathrm{a}, m$ & & \\
\hline
\end{tabular}

Table 2. ${ }^{1} \mathrm{H}-\mathrm{NMR}$ data of $\beta$-Solamarine (400 MHz, Pyridine- $\left.\mathrm{d}_{5}\right)$.

aOverlapped signals assigned by 2D NMR. $\mathrm{b} J$ values between parentheses in $\mathrm{Hz}$.

\begin{tabular}{|c|c|c|c|}
\hline $\mathrm{C}$ & $\delta \mathrm{ppm}$ & $\mathrm{C}$ & 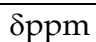 \\
\hline 1 & 37.7 & 24 & 29.8 \\
\hline 2 & 30.7 & 25 & 32.1 \\
\hline 3 & 78.6 & 26 & 51.1 \\
\hline 4 & 39.5 & 27 & 20.2 \\
\hline 5 & 141.3 & 1 & 100.8 \\
\hline 6 & 122.3 & 2 & 78.4 \\
\hline 7 & 32.9 & 3 & 79.0 \\
\hline 8 & 32.9 & 4 & 79.1 \\
\hline 9 & 50.9 & 5 & 77.4 \\
\hline 10 & 38.0 & 6 & 61.8 \\
\hline 11 & 21.7 & $1^{\prime \prime}$ & 102.5 \\
\hline 12 & 40.6 & $2^{\prime \prime}$ & 73.0 \\
\hline 13 & 46.0 & $3^{\prime \prime}$ & 73.0 \\
\hline 14 & 56.4 & $4^{\prime \prime}$ & 74.4 \\
\hline 15 & 33.1 & $5^{\prime \prime}$ & 68.6 \\
\hline 16 & 78.3 & $6^{\prime \prime}$ & 18.9 \\
\hline 17 & 64.0 & $1^{\prime \prime}$ & 103.4 \\
\hline 18 & 17.0 & $2^{\prime \prime}$ & 73.0 \\
\hline 19 & 19.9 & $3^{\prime \prime}$ & 73.2 \\
\hline 20 & 42.1 & $4^{\prime \prime}$ & 74.6 \\
\hline 21 & 16.2 & $5^{\prime \prime}$ & 70.0 \\
\hline 22 & 98.9 & $6^{\prime \prime}$ & 19.1 \\
\hline 23 & 35.2 & & \\
\hline
\end{tabular}

Table 3. ${ }^{13}$ CNMR data of $\beta$-Solamarine (100 MHz, Pyridine- $\left.\mathrm{d}_{5}\right)$. 


\subsubsection{Calystegines}

A mixture of calystegines could be identified in hairy root cultures of $S$. dulcamara L. The compounds were identified in semi-pure fractions. Identification based on comparison of their retention times and mass fragmentation patterns with those of standard calystegines as well as comparing to published data (Schimming et al., 1998). The identified compounds included calystegines $\mathrm{A}_{3}, \mathrm{~B}_{1}$ and $\mathrm{B}_{2}$ as major components. Calystegine $\mathrm{A}_{5}$ could be detected only in cultures grown under dark conditions (Fig. 7, B). Further chromatography of the bound fraction on different ion exchange resins lead to the isolation of calystegine $B_{2}$ in pure form. Its identity was further confirmed by comparison of ${ }^{13} \mathrm{C}$ NMR data (section 2.8.5) with those published for calystegine $B_{2}$ (Goldman et al., 1990). Other minor components were concentrated in some fractions and calystegine $B_{1}$-glucoside could also be identified by analysis of its mass spectral data (section 2.8.4). The detection of another major compound, which had a longer retention time than the other calystegines, 14.7 minutes,

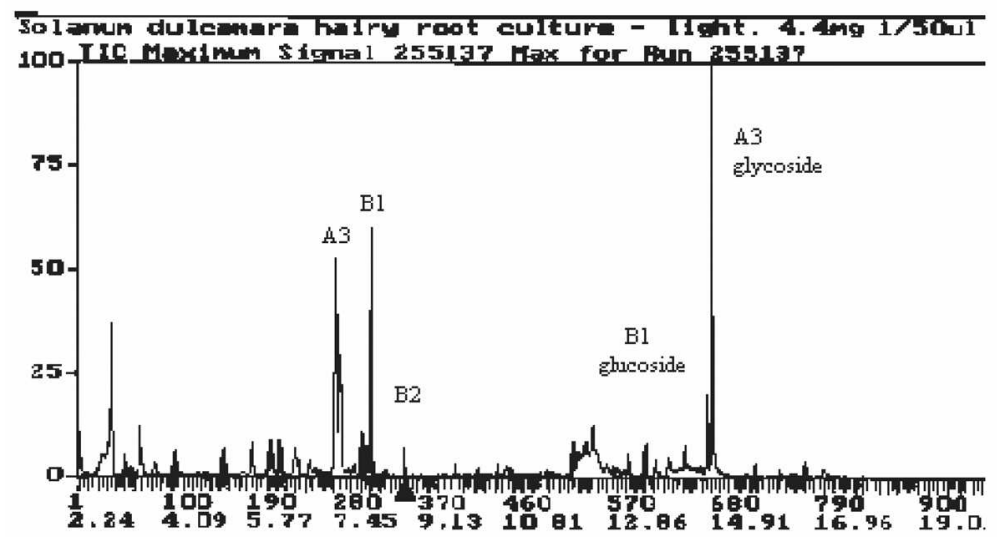

A

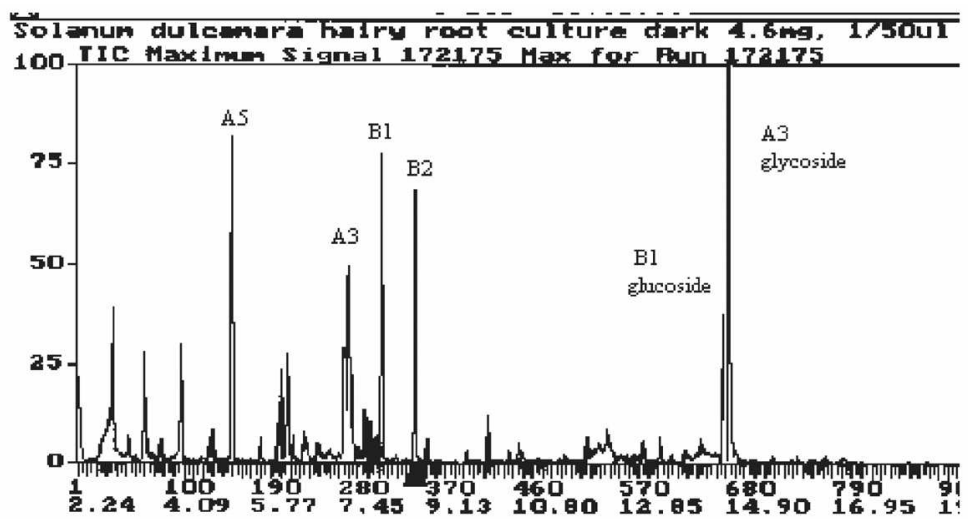

B

Fig. 7. GC traces of calystegines content of hairy roots grown under light (A) and in dark (B). 
which is very close to the retention time of $B_{1}$-glucoside (14.4 minutes), suggested that it might also be a glycoside. The mass fragmentation pattern (experimental, section 2.8.4) was typical of trihydroxylated nortropane derivatives (calystegine-A group). Hence, this compound is suggested to be calystegine $A_{3}$ or $/ A_{5}$ glycoside. It would be impossible to distinguish $\mathrm{A}_{3}$ and $\mathrm{A}_{5}$ glycosides without purification and NMR analysis. However this Aglycoside would be a novel compound.

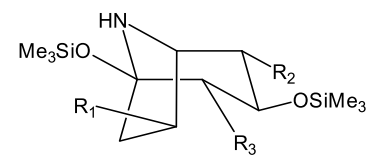

Calystegine $\mathrm{A}_{3}, \mathrm{R}_{1}=\mathrm{R}_{2}=\mathrm{H}, \mathrm{R} 3=\mathrm{OsiMe}_{3} ; \mathrm{m} / \mathrm{z} 375$

Calystegine $\mathrm{A}_{5}, \mathrm{R}_{1}=\mathrm{R}_{3}=\mathrm{H}, \mathrm{R}_{2}=\mathrm{O} \mathrm{NiMe}_{3} ; \mathrm{m} / \mathrm{z} 375$

Calystegine $\mathrm{B}_{1}, \mathrm{R}_{1}=\mathrm{R}_{3}=\mathrm{OSiMe}_{3}, \mathrm{R}_{2}=\mathrm{H} ; \mathrm{m} / \mathrm{z} 463$

Calystegine $\mathrm{B}_{2}, \mathrm{R}_{1}=\mathrm{H}, \mathrm{R}_{2}=\mathrm{R}_{3}=\mathrm{OsiMe}_{3} ; \mathrm{m} / \mathrm{z} 463$

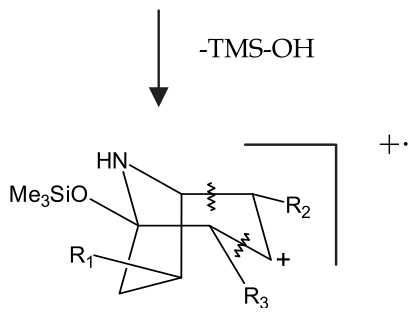

$\mathrm{m} / \mathrm{z} 286, \mathrm{~A}_{3}, \mathrm{~A}_{5} ; \mathrm{m} / \mathrm{z} 373, \mathrm{~B}_{1}$

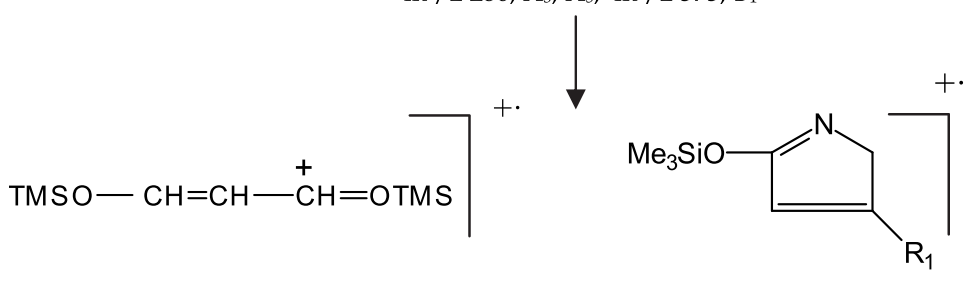

$\mathrm{m} / \mathrm{z} 217$<smiles>C[C@H](CO[Na])O[Na]</smiles>

$\mathrm{m} / \mathrm{z} 204$ $\mathrm{m} / \mathrm{z} 156, \mathrm{~A} 3, \mathrm{~A} 5$

$\mathrm{m} / \mathrm{z} 244, \mathrm{~B}_{1}$

$$
+\quad\left(\mathrm{CH}_{3}\right)_{3} \mathrm{SiOS} \stackrel{+}{\mathrm{S}}\left(\mathrm{CH}_{3}\right)_{2}
$$

$\mathrm{m} / \mathrm{z} 147$

Fig. 8. Major fragment ions in the Mass spectra of calystegines.

Other major unidentified compounds were also detected in the GC-MS trace of the bound fraction of the hairy root cultures. They are likely to be also novel polyhydroxy alkaloids according to their chromatographic behaviour on ion exchange resins and mass fragmentation patterns and are not accumulated in the whole plant (data not shown). It is worth noting that calystegines $A_{3}, A_{5}, B_{1}$ and $B_{2}$ have been identified before in nontransformed plants (Asano et al., 2001). The same research group also identified calystegine $\mathrm{N}_{1}$ that had not been detected in our root cultures. The glycosylated derivatives of 
calystegines $B_{1}$ and A-type are reported here for the first time from transformed root cultures of $S$. dulcamara L. They have not been reported before in the original plant. The Atype glycoside would be a novel natural product.

It is evident, from the data given above (experimental section 2.8.4), that the mass fragmentation pattern of the TMS derivatives of the different calystegines, mainly followed that described for the O-TMS derivatives (Molyneaux et al., 1996). Major fragment ions due to the loss of TMS-OH (-90 mu), were observed (ions at m/z: 286, for calystegines $A_{3}$ and $A_{5}$; 373 , for calystegine $B_{1}$ and 284 , for calystegine $B_{2}$ ).

In the case of A-type calystegines, the base peak was due to the 2-substituted pyrrolinium ion formed via cleavage of the six-member ring (fragment ion at $\mathrm{m} / \mathrm{z}$ 156). For the B-type

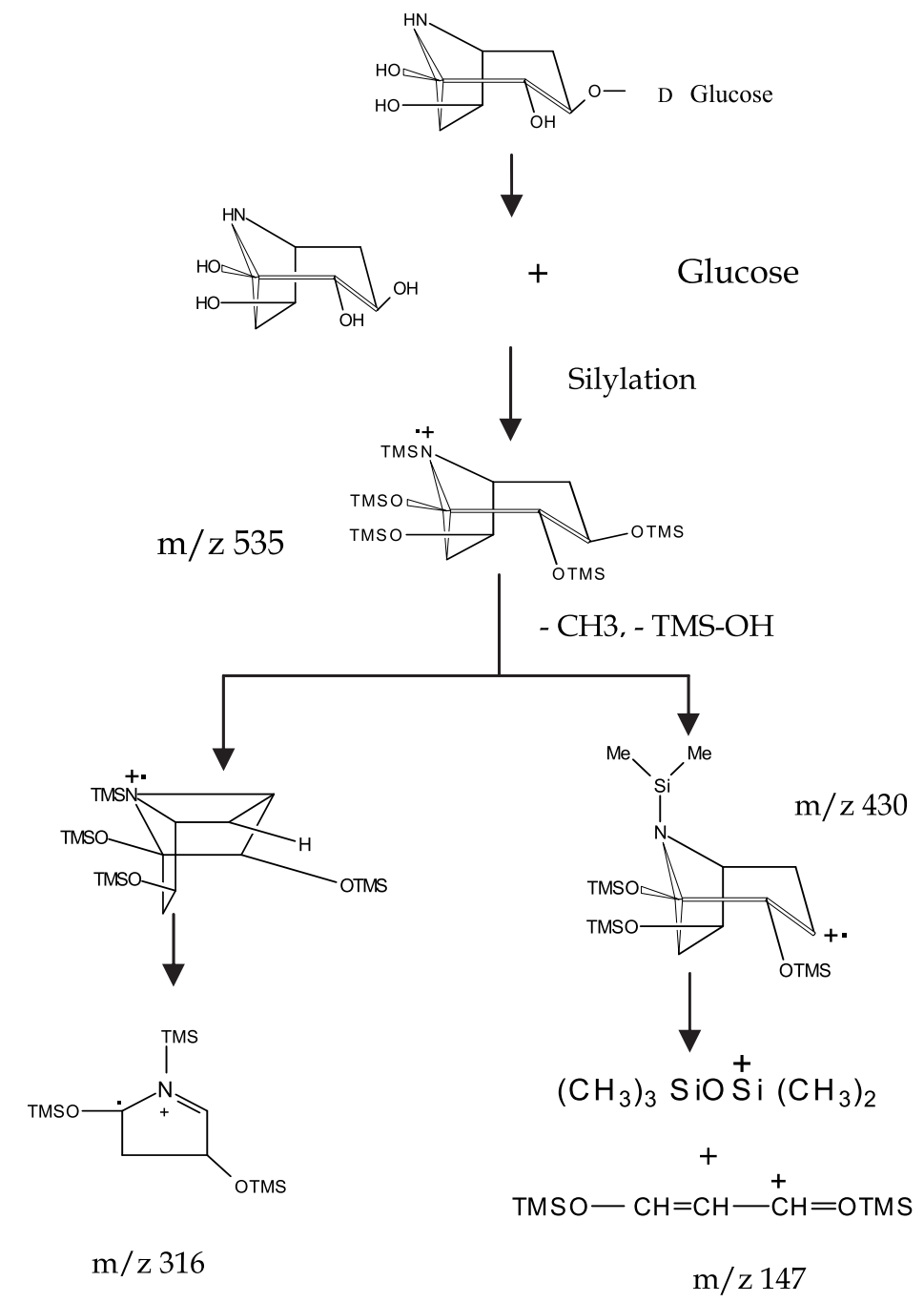

Fig. 9. Mass fragmentation pattern of calystegine $B_{1}$ glucoside 
calystegines, the base peak was at $\mathrm{m} / \mathrm{z} 244$, which was also due to the formation of the 2substituted pyrrolinium ion in the case of calystegine $B_{1}$, while in the case of calystegine $B_{2}$ this fragment ion was detected at a lower abundance (see experimental, section 2.8.4). Calystegine $\mathrm{B}_{2}$ showed a base peak ion at $\mathrm{m} / \mathrm{z} 217$. This is still a common ion fragment for TMS derivatives of polyhydroxylated compounds and sugars (DeJongh et al., 1969). Other fragments, which are characteristic of sugars, were also observed at $\mathrm{m} / \mathrm{z} 204,147$ and 129. The structures of these fragments are illustrated in Fig. (8). Surprisingly, the mass fragmentation pattern of calystegine $\mathrm{B}_{1}$-glucoside seems to have mainly proceeded via the route described for the persilylated TMS derivatives. Major fragments were observed due to loss of $\mathrm{CH}_{3}$ followed by loss of TMS-OH (ion at $\mathrm{m} / \mathrm{z} 430$ ). The base peak (at $\mathrm{m} / \mathrm{z} 316$ ) was due to the dihydropyrrolinium ion formed via the cleavage of a tricyclic ion. The fragment ions at m/z 217, 205 and 147 occurred at higher abundance than in the other calystegines, probably because they were also coming from the sugar part. A possible explanation is that the reaction under heating condition, has caused the hydrolysis of the glycoside and the silylation of the fourth hydroxyl group took place. The fragmentation pattern of this compound is illustrated in Fig. (9).

\section{Conclusion}

Hairy root cultures could be successfully established for S. dulcamara L. High transformation rates $(>90 \%)$ could be obtained and were attributable to a number of factors including selection of the bacterial strain; A. rhizogenes is known to be host specific with a narrower spectrum of susceptibility than A. tumefaciens. Another factor is the addition of acetosyringone as virulence gene inducer of Agrobacterium. Moreover, two compounds identified in the cultures by LC/MS (data not shown) as vanillic and ferulic acids may have contributed to the ease of transformation. Those molecules have the same structural features of the monocyclic polyphenolics known as the virulence-gene inducers which include acetophenones, syringaldehyde, vanillin, synapinic and syringic acids as well as their glycosylated derivatives (Stachel et al., 1985, Delmotte et al., 1991). Phytochemical investigation of $S$. dulcamara cultures revealed a complex pattern of secondary metabolites. Several compounds belonging to different chemical classes have been identified. Those included the triterpene betulinic acid, the steroid daucosterol (data not shown), the glycoalkaloid $\beta$-solamarine and a group of nortropane alkaloids, recently identified in the family Solanaceae (calystegines) in addition to the aforementioned phenolic derivatives. In general the profile of secondary metabolite production by the cultures was much similar to that of the original plants from which they were derived. Some metabolic shifts were observed as follows: the major compound in $S$. dulcamara hairy roots was a calystegine glycoside $\left(\mathrm{A}_{3} / \mathrm{A}_{5}\right)$, which was not synthesized by the original plant; betulinic acid which is isolated from the cultures could not be traced in the literature for other Solanum species or in the family Solanaceae. These differences could be attributed to the transformation process itself. The insertion of the transfer DNA from Agrobacterium is known to be a random process that is accompanied by addition or rearrangement deletions of sequences in the transformed plant cell DNA (Gheysen et al., 1989). Thus the insertion of the transfer DNA could have caused an interruption of certain genes that encode for certain steps in the secondary metabolic pathways. In brief, the use of transformed root cultures for production of secondary metabolites is very promising. The cultures were able to synthesize the target compounds at levels comparable to the original plants and showed both structural and metabolic stability over a long period (over two years). The shifts that were noticed in the 
metabolic pathways are not deleterious. Moreover, they can be used to produce novel compounds from those cultures. The cultures are amenable to techniques applied for product enhancing, like selection. Each root line is derived from individual transformation event that could give rise to different production capacity. The only limitation to the commercialization of hairy root cultures of this species is the complexity of the secondary metabolic profile. On the other hand they would be an excellent system for studying biosynthetic pathways for steroidal compounds and the calystegines.

\section{Reference}

Alvarez, M., Talou, J., Paniego, N. \& Giulietti, A. (1994). Solasodine production in transformed organ cultures (roots and shoots) of Solanum eleagnifolium Cav. Biotechnology Letters, 16, 393-396.

Argolo, A., Charlwood, B. \& Pletsch, M. (2000). The regulation of solasodine production by Agrobacterium rhizogenes transformed roots of Solanum aviculare. Planta Medica, 66, 448-451.

Asano, N. Yokoyama, K., Sakurai, M., Ikeda, K., Kizu, H., Kato, A., Arisawa, M., Hoke, D., Drager, B., Watson, A. A. \& Nash, R. J. (2001). Dihydroxynortropane alkaloids from calystegine-producing plants. Phytochemistry, 57, 721-726.

Asano, N., Kato, A. Miauchi, M., Kizu, H., Tomimori, T., matsui, K., Nash, R. \& Molyneux, R. (1997). Specific $\alpha$-galactosidase inhibitors, N-metyl calystegines: structureactivity relationships of calystegines from Lycium chinense. European Journal of Biochemistry, 248, 296-303.

Asano, N., Nash, R. J., Molyneaux, R. \& Fleet, G. (2000). Sugar-mimic glycosidase inhibitors: Natural occurrence, biological activity and prospects for therapeutic application. Tetrahedron Asymmetry, 11, 1645-1680.

Asano, N., Oseki, K., Tomioka, A., Kizu, H.\& Matsui, K. (1994). N-containing sugars from Morus alba and their glycosidase inhibitory activities. Carbohydrate Research, 259, 243-255.

Ascenão, L., Figueiredo, A.C., Barroso, J., Pedro, L., Schripsema, J., Deans, S. \& Scheffer, J. (1998). Plectranthus madagascariensis: Morphology of the glandular trichomes, essential oil composition and its biological activity. International Journal of Plant Science, 159, 31-38.

Atta-ur-rahman, N., choudhary, M. (1993). Steroidal Alkaloids, In: Methods in Plant Biochemistry, Alkaloids and Sulphur Compounds, Waterman, P. (ed.), Vol. VIII, chapter 13, pp. 473-510, Academic Press, London.

Baccou, J., Lambert, F. \& Sauvaire, Y. (1977). A spectrophotometric method for determination of total sapogenins. Analyst , 102, 458-465.

Briner, J. (1969). Determination of total steroid bases in Solanum species. Journal of Pharmaceutical Science, 58, 258-259.

Chilton, M., Tepfer, D., Petit, A, David, C. \& Tempè, J. (1982.) A. rhizogenes inserts T-DNA in the genome of the host plant root cells. Nature, 295, 432-434.

Crabbe, P., Fryer, C. (1982). Evaluation of chemical analysis for the determination of solasodine in Solanum laciniatum. Journal of Pharmaceutical Sciences, 71, 1356-1362.

DeJongh, D., Radford, T., Hribar, J., Hanessian, S., Bieber, M., Dawson, G. \& Sweeley, C. (1969). Analysis of trimethylsilyl derivatives of carbohydrates by gas chromatography and mass spectrometry. Journal of the American Chemical Society, 91, 1728-1740. 
Delmotte, F, Delay, D., Cizeau, J., Guerin, B. \& Leple, J. (1991). Agrobacterium vir-inducing activities of glycosylated acetosyringone, acetovanillone, syringaldehyde and syringic acid derivatives. Phytochemistry, 30, 3549-3552.

Drewes, F., Van Staden, J. (1995). Initiation of and solasodine production in hairy root cultures of Solanum mauritianum Scop. Plant Growth Regulation, 17, 27-31.

Ehmke, A., Eilert, E. (1993). Solanum dulcamara (bittersweet): Accumulation of steroidal alkaloids in the plant and different in vitro systems, In: Biotechnology in Agriculture and Forestry 21, Medicinal and Aromatic Plants IV, Bajaj, Y. (ed.), pp. 339-352, Springer-Verlag, Berlin.

Gamborg, O., miller, R. \& Ojima, K. (1968). Nutrient requirements of suspension cultures of soybean root cells. Experimental Cell Research, 50, 151-158.

Georgiev, M., Pavlov, A. \& Bley, T. (2007). Hairy root type plant in vitro systems as sources of bioactive substances. Applied Microbiology and Biotechnology, 74:1175-1185.

Ghyesen, G., Herman, L., Breyne, P., Van Montagu, M. \& Depicker, A. (1989). Agrobacteriium tumifaciens as a tool for the genetic transformation of plants, In: Genetic transformation and expression, Butler, L., Harwood, C. \& Moseley, B. (eds.), pp.151-174, Intercept Ltd., England.

Goldman, A., Milat, M., Ducort, L., Lallemand, J., Maille, M., Lepingle, A., Charpin, I. \& Tepfer, D. Tropane derivatives from Calystegia sepium. Phytochemistry, 29, 2125-2127.

Hamill, J., Lidgett, A. (1997). Hairy root cultures: Opportunities and key protocols for studies in metabolic engineering. In: Hairy Roots: Culture and Applications, Doran, P. (ed.), pp 1-29, Harwood Academic Publishers, Australia.

Hamill, J., Rounsley, S., Spencer, A., Todd, G., Rhodes, M.J.C. (1991). The use of the polymerase chain reaction in plant transformation studies. Plant Cell Reports, 10, 221-224.

Hegnauer, R. (1989). Solanaceae, In: Chemo-taxonomie Der Pflanzen, Birkhauser, Vol. VI, pp. 403-452, Verlag, Switzerland.

Hooykaas, P., Klapwijk, M., Nuti, M., Schilperoort, P. \& Rorsch, A. (1977). Transfer of the Agrobacterium tumefaciens Ti plasmid to avirulent Agrobacteria and Rhizobium ex planta". Journal of General Microbiology, 98, 477-484.

Ikenaga, T., Oyama, T. \& Muranaka, T. (1995). Growth and steroidal saponin production in hairy root cultures of Solanum aculeatissimum. Plant Cell Reports, 14, 413-417.

Kittipongapatana, N., Hock, R. \& Porter, J. (1998). Production of solasodine by hairy root cultures of Solanum aviculare Forst. Plant Cell, Tissue and Organ Culture, 52, 133-143.

Mathé, JR., Mathé, I, Botz, L. \& Koch, L. (1986). Possibilities of Solanum alkaloids production in European temperate zone. Acta Horticultura, 188, 193-201.

Mathé, JR., Mathé, I. (1979). Variation in Alkaloids in Solanum dulcamara L., In: The Biology and Taxonomy of the Solanaceae, Hawkes, J., Lester, R. \& Skelding, A. (eds), pp. 211222, Academic press, London.

Metcalf, C., Chalk, L. (1957). Solanaceae, In: Anatomy of the Dicotyledons. Vol. II., pp. 965-978, Clarendon Press, UK.

Molyneaux, R., Nash, R. \& Asano, N. (1996). The chemistry and biological activity of calystegines and related nortropane alkaloids, In: Alkaloids: Chemical and Biological Perspectives, Pelletier, S. (ed.), volume II, chapter 4, pp. 303-343, Elsvier Science Ltd., UK.

Murashige, T., Skoog, F. (1962). A revised medium for rapid growth and bioassays with tobacco tissue cultures. Physiologia Plantarum, 15, 473-497. 
Nash, R., Rotschild, M., Porter, A., Watson, A., Waigh, R. \& Waterman, P. (1993). Calystegines in Solanum and Datura species and the death's head hawk-moth (Acherontia atropus). Phytochemistry, 34, 1281-1283.

Porter, J. (1991). Host Range and implication of plant infection by Agrobacterium rhizogenes. Critical Reviews in Plant Sciences, 387-421.

Rhodes, M., Robins, R., Hamill, J., Parr, A. \& Walton, N. (1987). Secondary product formation using Agrobacterium rhizogenes-transformed "hairy root" cultures. IAPTC Newsletters, 53, 2-15.

Ripperger, H. (1996). 22, 26-epiminocholestane alkaloids with unusual (20R) configurations from Solanum species. Phytochemistry, 41, 1629-1631.

Rönsch, H., Schreiber, K. (1966). Solanum Alakloide-LXXII. Uber $\delta_{1^{-}}$und $\delta$-solamarin, zwei neue tomatidenol glycoside aus Solanum dulcamara L. Phytochemistry, 5, 1227-1233.

Sato, Y., Miller, H. \& Mosettig, E. (1951). Degradation of solasodine. Journal of the American Chemical Society, 73, 5009-5011.

Schenk, R., Hildebrandt, A. (1972). Medium and techniques for induction of monocotyledonous and dicotyledonous plant cell cultures. Canadian Journal of Botany, 50, 199.

Schimming, T., Tofern, B., Mann, P., Richter, A., Jennett-Siems, K., Drager, B., Asano, N., Gupta, M., Correra, M. \& Eich, E. (1998). Distribution and taxonomix significance of calystegines in the Convolvulaceae. Phytochemistry, 49, 1989-1995.

Schripsema, J., Meijer, A., Van Iren, F., Hoopen, H. \& Verpoorte, R. (1990). Dissimilation curves as a simple method for the characterisation of growth of plant cell suspension cultures. Plant Cell, Tissue and Organ Culture, 22, 55-64.

Stachel, S., Messens, E, Van Montagu, M. \& Zambryski, P. (1985). Identification of the signal molecules produced by wounded plant cells that activate T-DNA transfer in Agrobacterium tumefaciens. Nature, 318, 624-629.

Subroto, M., Doran, P. (1994). Production of steroidal alkaloids by hairy roots of Solanum aviculare and the effect of gibberelic acid. Plant Cell, Tissue and Organ Culture, 38, 93102.

Tepfer, D., Goldman, A., Pamboukdjian, N., Maille, M., Lepingle, A., Chevalier, D., Denarie, J. \& Rosenberg, C. (1988). A plasmid of Rhizobium meliloti 41 encodes catabolism of two compounds from root exudates of Calystegia sepium. Journal of Bacteriology, 170, 1153-1161.

Toshinori, N., Teruhiko, Y., Junko, O., Sadao, S. (1993). Steroidal alkaloids from tomato stock. Phytochemistry, 34, 1153-1157.

Usubillaga, A., Aziz, I., Tettamanizi, M., Waibel, R. \& Achenbach, H. (1997). Steroidal alkaloids from Solanum sycophanta. Phytochemistry, 44, 537-543.

Watson, A., Fleet, G., Asano, N., Molyneaux, R. \& Nash, R. (2001). Polyhydroxylated alkaloids, natural occurrence and therapeutic applications. Phytochemistry, 56, 265-295.

Willuhn, G. (1966). Undersuchungenzur chemi-schen differenzierung bei S. dulcamara L. I. Genetische fixierung der unter-schiedlichen steroidalkaloid fÜhrung. Planta Medica, 14, 408-420.

Yu, S., Kwok, K. \& Doran, P. (1996). Effect of sucrose, exogenous product concentration and other culture conditions on growth and steroidal alkaloid production by Solanum aviculare hairy roots. Enzyme and Microbial Technology, 18, 238-243. 


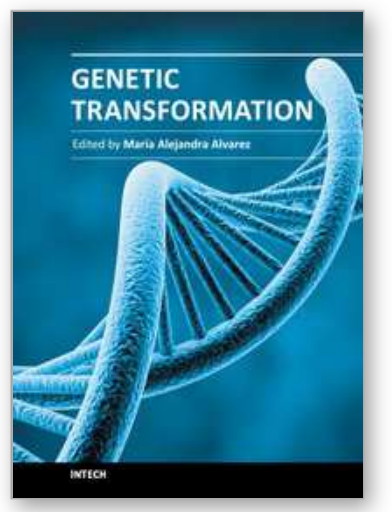

\author{
Genetic Transformation \\ Edited by Prof. MarÃa Alvarez
}

ISBN 978-953-307-364-4

Hard cover, 328 pages

Publisher InTech

Published online 06, September, 2011

Published in print edition September, 2011

Genetic transformation of plants has revolutionized both basic and applied plant research. Plant molecular biology and physiology benefit from this power fool, as well as biotechnology. This book is a review of some of the most significant achievements that plant transformation has brought to the fields of Agrobacterium biology, crop improvement and, flower, fruit and tree amelioration. Also, it examines their impact on molecular farming, phytoremediation and RNAi tools.

\title{
How to reference
}

In order to correctly reference this scholarly work, feel free to copy and paste the following:

Amani M. Marzouk, Stanley G. Deans, Robert J. Nash and Alexander I. Gray (2011). Transformed Root Cultures of Solanum dulcamara L.: A Model for Studying Production of Secondary Metabolites, Genetic Transformation, Prof. MarÃa Alvarez (Ed.), ISBN: 978-953-307-364-4, InTech, Available from:

http://www.intechopen.com/books/genetic-transformation/transformed-root-cultures-of-solanum-dulcamara-l-amodel-for-studying-production-of-secondary-metabo

\section{INTECH}

open science / open minds

\section{InTech Europe}

University Campus STeP Ri

Slavka Krautzeka 83/A

51000 Rijeka, Croatia

Phone: +385 (51) 770447

Fax: +385 (51) 686166

www.intechopen.com

\section{InTech China}

Unit 405, Office Block, Hotel Equatorial Shanghai

No.65, Yan An Road (West), Shanghai, 200040, China

中国上海市延安西路65号上海国际贵都大饭店办公楼405单元

Phone: +86-21-62489820

Fax: +86-21-62489821 
(C) 2011 The Author(s). Licensee IntechOpen. This chapter is distributed under the terms of the Creative Commons Attribution-NonCommercialShareAlike-3.0 License, which permits use, distribution and reproduction for non-commercial purposes, provided the original is properly cited and derivative works building on this content are distributed under the same license. 